\title{
Раннефольклорные обрядовые жанры традиционной культуры хори-бурят
}

\section{Лидия Данииловна Дашиева ${ }^{1}$}

${ }^{1}$ Институт монголоведения, буддологии и тибетологии СО РАН (д. 6, ул. Сахъяновой, 670047 Улан-Удэ, Российская Федерация) доктор искусствоведения, ведущий научный сотрудник (iD) 0000-0003-0492-7252. E-mail: dashieva2006@yandex.ru

(С) КалмНЦ РАН, 2021

(С Дашиева Л. Д., 2021

Аннотация. Введение. В данной статье продолжено исследование традиционной музыкальной культуры восточных хори-бурят, основанное на архивном материале аудиоколлекции известного ученого востоковеда Пурбо Балдановича Балданжапова (1921-1991). Целью исследования является репрезентация раннефольклорных жанров обрядовой традиционной музыки восточных хори-бурят. Методы исследования. В статье используются методы жанрового и структурно-типологического анализа фольклорных произведений, записанных П. Б. Балданжаповым. Изучение хори-бурятской обрядовой песенной традиции, как системы, повлекло привлечение структурно-функционального метода, позволившего рассмотреть разные аспекты ритуально-обрядового комплекса восточных хори-бурят. Результаты. Традиционная музыка восточных хори-бурят дифференцируется на две жанровые группы (обрядовую и необрядовую). Обрядовая музыка коллекции П. Б. Балданжапова включает свадебные песни (уусын дуунууд), древний обрядовый танец нэрьелгэ и сопровождающие его песни (нэрьелгын или нэрьеэнэй дуунууд), прославление лошади (мориной соло), буддийские песнопения маани. Во вторую группу входят жанры необрядовой сферы - улигеры (үльгэрнууд), исторические песни (түҮхын дуунууд) о Шилдэ занги, восхваления родителей (магтаалнууд), песни кольца (бэһэлигэй дуунууд), шуточные песни (шог дуунууд). В статье особое внимание уделено уникальным, но уже утраченным жанрам обрядовой музыки хори-бурят - нэрьелгын дуунууд, сопровождающим ритуальный танец нэрьелгэ и прославления победившей в скачках лошади мориной соло. Анализ семантического содержания поэтических текстов и музыкальных интонаций позволяет отнести эти жанры к раннефольклорному пласту традиционной музыки восточных хори-бурят. Анализ памятников их обрядового песенного фольклора способствует в будущем проведению реконструкции этих редких жанров в контексте сравнительно-исторического изучения культурных традиций тюрко-монгольских народов.

Ключевые слова: обрядовая музыка, раннефольклорные жанры, традиционная культура, хори-буряты, П. Б. Балданжапов

Благодарность. Статья выполнена в рамках государственного задания - проект «Письменные традиции народов Байкальского региона в контексте историко-культурного наследия России и Внутренней Азии» (номер госрегистрации: 121031000263-3). 
Для цитирования: Дашиева Л. Д. Раннефольклорные обрядовые жанры традиционной культуры хори-бурят // Монголоведение. 2021. Т. 13. №. 4. С. 704-712. DOI: 10.22162/25001523-2021-4-704-712

\title{
Traditional Culture of Khori Buryats: Early Folklore Ritual Genres Revisited
}

\section{Lidiya D. Dashieva ${ }^{1}$}

${ }^{1}$ Institute for Mongolian, Buddhist and Tibetan Studies, Siberian Branch of the RAS (6, Sakhyanova St., 670047 Ulan-Ude, Russian Federation)

Dr. Sc. (Art History), Leading Research Associate

iD 0000-0003-0492-7252. E-mail: dashieva2006@yandex.ru

\author{
(C) KalmSC RAS, 2021
}

(C) Dashieva L. D., 2021

\begin{abstract}
This article continues the study of the traditional musical culture of the Eastern KhoriBuryats, based on rare archival material of the audio collection of the famous orientalist Purbo Baldanovich Baldanzhapov (1921-1991). The research was started by the author in 2014 in the article "Materials of P. B. Baldanzhapov as a source for studying the song tradition of the Khori-Buryats". The aim of this article is to represent the early folklore genres of the ceremonial traditional music of the Eastern Khori-Buryats. In the article the methods of genre and structuraltypological analysis of folklore works recorded by P. B. Baldanzhapov were used. The study of the Khori-Buryat ritual song tradition, as a system, entailed the involvement of a structural and functional method, which allowed us to consider various aspects of the ritual and ritual complex of the eastern Khori-Buryats. The traditional musical culture of the Eastern KhoriBuryats can be divided into two genre groups (ceremonial and non-ceremonial). The ritual music of P.B. Baldanzhapov's audio collection includes wedding songs (Uusyn duunuud), the ancient ritual dance Neryelge and accompanying songs (Neryelgyn or Neryeenei duunuud), the glorification of the horse by Morinoy solo, Buddhist Maani chants. The second group includes such genres of non-ritual sphere as uligers (Ulgernuud), historical songs (Tuuhyn duunuud) about Shilde Zangi, magtals to parents (Magtaalnuud), ring songs (Beheligey duunuud), comic songs (Shog duunuud). In this article, special attention is paid to the unique, but already lost genres of ritual music of Khori-Buryats - Neryelgyn duunuud, accompanying the ritual dance of Neryelge and the glorification of the horse (Morinoy solo), who won the race. The analysis of the semantics of poetic texts and musical intonations of Neryelgyn duunuud and Morinoy solo allows us to attribute these genres to the early folklore layer of the traditional musical culture of the Eastern Khori-Buryats and to reveal the semantic connection with the mythology and religion of the early nomads. Of course, in the future research it is necessary to continue studying the works of non-ritual traditional music of the Khori-Buryats from the collection of P.B. Baldanzhapov. The analyses of these samples of song folklore might allow to carry out the notation of Morinoy's solo samples with their subsequent musical analysis and publication. One of the promising areas of research may be the reconstruction of these rare and unique genres of ritual music of the Khori-Buryats in the context of a comparative historical study of the cultural traditions of the Turkic-Mongolian peoples.
\end{abstract}

Keywords: ritual music, early folklore genres, traditional culture, Khori-Buryats, P. Baldanzhapov

Acknowledgements. The reported study was funded by government assignment, project no. 121031000263-3 'Writing Traditions of Baikal Peoples in the Context of Historical and Cultural Heritage of Russia and Inner Asia'. 


\section{Монголоведение • Mongolian Studies • 2021 • T. 13 • № 4}

For citation: Dashieva L. D. Traditional Culture of Khori Buryats: Early Folklore Ritual Genres Revisited. Mongolian Studies (Elista). 2021; 13(4): 704-712. (In Russ.). DOI: 10.22162/25001523-2021-4-704-712

\section{Введение}

В настоящей статье продолжено исследование традиционной культуры восточных хори-бурят, основанное на архивном материале аудиоколлекции известного ученого востоковеда Пурбо Балдановича Балданжапова (1921-1991), начатое автором в статье «Материалы П. Б. Балданжапова как источник изучения песенной традиции хори-бурят» [Дашиева 2014]. Широкий спектр научной деятельности П. Б. Балданжапова включает историографию, источниковедение, буддологию и изучение языка и культуры народов Центральной Азии. Кроме того, Пурбо Балданович проводил экспедиционную работу, принимая активное участие в фольклорно-этнографической экспедиции в 1958 г. в районах проживания восточных хори-бурят (Агинский, Ононский, Хилокский, Могойтуйский районы Агинского Бурятского автономного округа Читинской области; ныне Забайкальский край), в 1962 г. у хонгодоров (Тункинский район Бурятской АССР; ныне Республика Бурятия (далее - РБ)). Материалы этих экспедиций вошли в аудиоколлекцию П. Б. Балданжапова, хранящуюся в фонофонде Центра восточных рукописей и ксилографов (далее - ЦВРК) Института монголоведения, буддологии и тибетологии СО РАН (далее - ИМБТ СО РАН). Архивные материалы П. Б. Балданжапова (инвентарный номер 3504, 27 единиц хранения), зафиксированные в 1958 г., являются самыми ранними в фонофонде ЦВРК, что, безусловно, придает наибольшую значимость его коллекции. К сожалению, оригиналы не сохранились, но перезапись на магнитофонную ленту (дубликаты) была осуществлена хранителем Г. Д. Фроловой в 1996 г., дубликаты оцифрованы Л. Д. Дашиевой в 2007 г.

\section{Методы исследования}

В статье используются методы жанрового и структурно-типологического анализа фольклорных произведений, записанных П. Б. Балданжаповым. Изучение хори-бурятской обрядовой песенной традиции, как системы, повлекло привлечение структурно-функционального метода, позволившего рассмотреть разные аспекты ритуально-обрядового комплекса восточных хори-бурят.

\section{Жанровая типология материалов коллекции П. Б. Балданжапова}

Анализ жанрового состава аудиоколлекции П. Б. Балданжапова позволяет дифференцировать фольклорные записи на две группы: 1) обрядовая музыка хори-бурят: свадебные песни (уусын дуунууд), древний обрядовый танец нэрьелгэ и сопровождающие его песни (нэрьелгын или нэрьеэнэй дуунууд), прославление лошади (мориной соло), буддийские песнопения (маани); 2) необрядовая музыка хори-бурят, включающая улигеры (үльгэрнууд), исторические песни (түҮхын дуунууд) о Шилдэ занги, восхваление родителей (магтаалнууд), песни кольца (бэһэлигэй дуунууд), шуточные песни (щог дуунууд).

Особую жанровую группу в аудиоколлекции П. Б. Балданжапова составляют бурятские героические сказания үльгэрнууд. Важной заслугой ученого стали аудиозаписи улигеров от выдающихся хори-бурятских сказителей Галсанжамсо 


\section{Материалы IV Международного семинара «Письменное наследие \\ и актуальные проблемы истории и культуры монгольских народов», посвященного 100-летию со дня рождения Пурбо Балдановича Балданжапова}

Тыхеева и Лхасарана Бальчинова. Тексты улигеров были опубликованы в книге «Агын ҮльгэрнүҮд» («Агинские улигеры»), изданной в 1961 г. [Балданжапов 1961]. Тексты улигеров «Боро соохор моритой Боронтуу мэргэн» («Боронту мэргэн на серо-пестром коне»), «ЗҮгы мэргэн хаанай Мижэд хүбүун» («Мижэд, сын Зүгы мэргэн хана»), «Үншэн сагаан ботогон» («Сиротка белый верблюжонок») были записаны у Галсанжамсо Тыхеева. В фонофонде ЦВРК хранятся цифровые копии семи улигеров, из которых три («Бальжан хатан» («Бальжан хатан»), «Алтан Шаахай Мунгэн Шаахай хоёр» («Алтан Шаахай и Мунгэн Шаахай»), «Арбан долоон наһатай Алтан Сэндэл нойон хаан» («Семнадцатилетний Алтан Сэндэл нойон хан») были записаны в селах Новая Заря и совхозе «Красная Ималка» Ононского района Читинской области от указанных выше сказителей в 1958 г.

Четыре улигера хонгодоров «Эрэ Орзо мэргэн» («Эрэ Орзо меткий»), «Yгытэй хүбүYн» («Парень-бедняк»), «Хаан Харангуй» («Хан Харангуй») и улигер с песенным разделом, записанные П. Б. Балданжаповым в 1962 г. от сказителей Дагбы Аюшеева и Дармы Забанова в селах Монды и Харбяты Тункинского района Бурятской АССР, представляют западнобурятскую улигерную традицию.

Анализ звуковысотно-ладовой и ритмической организации хори-бурятского улигера «Арбан долоон наһатай Алтан Сэндэл нойон хаан» («Семнадцатилетний Алтан Сэндэл нойон хан») представлен в статьях автора [Дашиева 2014: 65-76; Дашиева 2009б]. По нашему мнению, этот удивительный хори-бурятский улигер по музыкальным особенностям имеет очевидное сходство с западной эхирит-булагатской улигерной традицией.

\section{О древнем обрядовом танце хори-бурят нэрьелгэ}

В первой жанровой группе особое внимание привлекают редкие жанры обрядовой музыки хори-бурят - нэрьелгын дуунууд или нэрьенэй дуунууд, сопровождающие ритуальный танец нэрьелгэ, и прославления победившей в скачках лошади мориной соло. Эти жанры относятся к уже утраченной традиции в хори-бурятском фольклоре.

Древний обрядовый танец нэрьелгэ у восточных хори-бурят, проживающих в Агинском Бурятском округе Забайкальского края и на территории РБ, как уже было отмечено выше, давно ушел в прошлое. В настоящее время танец нэрьелгэ со всеми его составляющими (форма, тексты песен, кинетика) сохранился лишь в фольклоре шэнэхэнских хори-бурят, мигрировавших во Внутреннюю Монголию Китайской Народной Республики в начале XX в. Нотировки четырнадцати образцов обрядовых песен нэрьеэнэй дуунууд, записанных у шэнэхэнских бурят, опубликованы А. Нумой в нотном сборнике «Буряад-монгол арадай дуунууд» («Бурят-монгольские народные песни») [Нумаа 2003: 87-100]. Что касается западных бурят, то в их традиционной культуре этот танец никем не был зафиксирован [Дашиева 2017].

Известному бурятскому ученому, фольклористу и этнографу Д. С. Дугарову удалось собрать, записать и опубликовать ценные сведения о бытовании хори-бурятского нэрьелгэ, исследованию которого была посвящена глава в его монографии «Исторические корни белого шаманства», написанная на материале обрядового фольклора бурят [Дугаров 1991: 183-213]. Д. С. Дугаров впервые выполнил нотировки уникальных образцов нэрьелгын дуунууд, сопровождаю- 
щих хори-бурятский танец нэрьелгэ в фольклоре агинских хори-бурят [Дугаров 1964: 67-70].

Нэрьелгэ в переводе означает «громыхание» или «грохотание» (от слова «нэрьехэ» 'поднимать шум, греметь, грохотать') [Черемисов 1973: 339; Дугаров 1991: 184]. У западных бурят слово нэрьеэр означает «удар грома» или «удар бога-громовержца». Имя этого верховного бога - Айа. По сведениям Д. С. Дугарова, именно богу Айа буряты посвящали грандиозные обрядовые жертвоприношения тэнгри тайха ('жертвоприношение небу') [Дугаров 1991: 184]. Частью этого ритуала был древний хори-бурятский танец нэрьелгэ. По-видимому, утратив свою сакральность, он превратился в игру-состязание.

Из описания нэрьелгэ выделяются два варианта: 1) некруговой танец шеренгами или «стенками» и 2) круговой танец, аналогичный ёхору [Дашиева 2005: 47].

В одном из ранних письменных источников, в статье «Игры и увеселения агинских бурят», С.-Д. Шагдарон и Б.-Д. Очиров впервые дали описание нэрьелгэ [Шагдарон, Очиров 1909: 465-482]. По их сведениям, «в игре нырхэлгэ (ныргэлгэ) [курсив мой. - Л. Д.] присутствующие делятся на две партии, строятся в шеренгу друг против друга, образуя две сплошные стены. Покачиваясь в такт с боку на бок, одна из партий запевает песню. Ей отвечает другая партия своей песней, и тоже покачиваясь. Затем первая заводит другую песню, вторая отвечает также особой песней. Таким образом, обе партии обмениваются песнями» [Шагдарон, Очиров 1909: 468], причем исследователи отмечают, что «круговое гулянье и нырхэлгэ (ныргэлгэ) [курсив мой. — Л. Д.] продолжаются иногда до поздней ночи, а то и до рассвета» [Шагдарон, Очиров 1909: 468]. Подчеркнем, что уже в начале XX в. нэрьелгэ зафиксирован как игра-состязание, во время которого происходил обмен песнями дуу андалдаха ('обмениваться песнями'). По-видимому, такая игра типологически была близка песенным турнирам [Дашиева 2005: 46].

В осмыслении сакрального содержания нэрьелгэ большое значение имеет анализ поэтического текста, выявляющий семантическую связь с мифологией и религией ранних кочевников:

Нэрье, нэрье, нэрьеэл бэри, һөө! Айэ, һөө! Нэрье, нэрье, нэрье бэри! Нарһан модоной орой дээхэнүр, Наратал тэнгериин оёор доохонуур. Нэрье, нэрье, нэрьеэл бэри, һөө! Айэ, һөө! Нэрье, нэрье, нэрье бэри!
Греми, греми, ещё пуще греми, эй! Айэ, эй! Греми, греми, греми же пуще! Над вершинами леса соснового, Под дном неба солнечного. Греми, греми, ещё пуще греми, эй! Айэ, эй! Греми, греми, греми же пуще!

[Дугаров 1964: 67-70]

Подлинное значение поэтического текста песни «Нарһан модоной орой дээхэнүур» («Над вершинами деревьев сосновых») давно уже утрачено, но необходимо подчеркнуть, что во многих образцах нэрьелгын дуунууд присутствует устойчивое заклинательное слово нэрье ('греми'), обращенное к богу-громовержцу Айа. В выражении «дно неба» (тэнгэриин оёор) отражается древнейшее мифологическое представление предков бурят, для которых небо мыслилось огромным, бескрайним пространством, имеющим крышу и дно [Дугаров, Куницын 1997: 378]. 
Интонация припева «Нэрье, нэрье, нэрьеэл бэри һөө!» основана на квартовых скачках призывного характера $(h-e, a-d)$. Очевидно, это и есть обращение к богу-громовержцу Айа. Четкая ритмоформула подчеркивает согласованность движений участников древнего танца нэрьелгэ. Кроме того, одним из традиционных элементов бурятской интонации является нисходящий заключительный мелодический оборот в объеме кварты $(d-h-a)$ [Дашиева 2005: 49].

Одним из вариантов нэрьелгэ является круговой танец или хоровод, напоминающий один из самых популярных и любимых бурятских танцев ёхор (ёохор), исследованию которого посвящена монография автора «Бурятский круговой танец ёхор: историко-этнографический, ладовый, ритмический аспекты» [Дашиева 2009а]. Еще в начале XX в. в рукописи агинского бурята Цыбика Онгодова (1831-1910) присутствует одно из первых упоминаний о хороводе хори-бурят. Он пишет: «Хоровод составляется из смешанного круга больших и малых, без различия пола и порядка. Все молодые (потому что старики в плясках и хороводах не участвуют) поют хороводные песни, покачиваясь с боку на бок всем хороводом» (цит. по: [Дугаров 1991: 183]). Очевидно, хори-бурятский нэрьелгэ в форме круга имел генетическую связь с круговым западнобурятским танцем ёхор (ёохор).

\section{Прославление победившей в скачках лошади мориной соло}

Другим жанром традиционной музыкальной культуры восточных хори-бурят является прославление победившей в скачках лошади мориной соло (морин - 'лошадь', соло - 'слава, известность; хвалебная песнь, ода, воспевание, прославление') [Шагдаров, Черемисов 2008: 178].

В аудиоколлекции П. Б. Балданжапова зафиксированы три образца мориной соло, записанные в Ононском районе Агинского Бурятского автономного округа Читинской области от Галсанжамсо Тыхеева и Дугдана Бадмаева. Эти образцы отличаются устойчивым поэтическим текстом, в котором восхваляются внешние черты и лучшие качества победившей лошади: сила, ловкость, быстрота, смелость и др. [Магтаал, үреэл, соло 1993: 66-74].

Интерес представляет ранний текст мориной соло, записанный у монголов и переведенный на русский язык миссионером Яковом Чистохиным. Текст мориной соло был опубликован в 1894 г. в Известиях Восточно-Сибирского отдела ИРГО (Императорского Русского Географического общества) [Чистохин 1894: 139-140]:

«О, счастливейший юноша, который сидел на этом коне!

Где привязывал его, там лусуты усмирялись.

Ноздри этого коня подобны раковине «дун».

Прекрасные его глаза подобны подзорной трубе,

Зубы его подобны жесткому серебру Хac,

Уши его небольшие, тонкие, правильные и красивые,

Язык его подобен круглому серебру Голяру.

Как загривок, так и бедра его полны и жирны.

Мышцы и жилы его все в совершенстве,

Шея его крута, все же его ребра соединены друг с другом.

Позвоночный его хребет сросшийся (без позвонков).

Спина его подобна спине павлина. 


\section{Монголоведение • Mongolian Studies • 2021 • T. 13 • № 4}

Величина его подобна величине изюбра и других больших зверей!

Грива его не густа и красива,

Осанка же его картинна.

Когда пробегает большие степи, прибавляет попрыску,

А если пробежит еще, то прибавит ускоку и делается ретивее.

Бесконечные и скорые степи бежит подобно одному шагу.

Во время бега рассматривает он дальнейших небожителей.

Из пернатых белая лебедь не догонит его полетом.

Из четвероногих дикие лошади (хуланы) прытью своею не задавят его.

Пред полным собранием пира, перед распространенною великою верою

Сделался известным Зангея Падары (чиновник округа).

Ясный Дари, молодой Шанхар, лысый хая, шумный ястреб, суровая пуля,

Вынеженный и выхоленный бегун, от которого держу в руках золотой

Повод, которому приношу серебряную хвалу» [Чистохин 1894: 139-140].

Анализ вербального текста мориной соло позволяет подчеркнуть высокопарный одический стиль в описании внешних физических параметров победившей в скачках лошади. Например, ее зубы и язык сравниваются с серебром, ноздри - с морской раковиной, глаза - с подзорной трубой, спина - с павлином, размеры - с изюбром и т. п. При прославлении лошади восхваляются ее сила, выносливость, скорость, внешняя красота и другие качества, обеспечившие лидерство и победу. Кроме того, большое значение имеет мелодическое строение мориной соло, для которого характерен речитативный склад.

Из необрядовой жанровой сферы аудиоколлекции П. Б. Балданжапова были рассмотрены песни кольца бэһэлигэй дуунууд и, как было указано выше, улигеры [Дашиева 2014: 65-76].

\section{Заключение}

Анализ семантики поэтических текстов и музыкальных интонаций нэрьелгын дуунууд и мориной соло позволяет отнести эти жанры к раннефольклорному пласту традиционной музыкальной культуры восточных хори-бурят. В дальнейшем необходимо продолжить изучение фольклорных произведений необрядовой традиционной музыки хори-бурят из коллекции П. Б. Балданжапова, а также выполнить нотирование образцов мориной соло с их последующим музыкальным анализом и публикацией. Кроме того, одним из перспективных направлений исследования может стать реконструкция этих редких и уникальных жанров обрядовой музыки хори-бурят в контексте сравнительно-исторического изучения культурных традиций тюрко-монгольских народов.

\section{Литература}

Балданжапов 1961 - Балданжапов П. Б. Агын ульгэрнууд (= Агинские улигеры) / запись, подг. к публ., вст. ст. и обработка П. Б. Балданжапова. Улан-Удэ: Бурят. кн. изд-во, 1961. 127 с. (На бур. яз.)

Дашиева 2005 - Дашиева Л. Д. Традиционная музыкальная культура бурят: учебно-методическое пособие. Улан-Удэ: Изд-во ОАО «Республиканская типография», 2005. $188 \mathrm{c.}$

Дашиева 2009а - Дашиева Л. Д. Бурятский круговой танец ёхор: историко-этнографический, ладовый, ритмический аспекты. Улан-Удэ: Изд-во БНЦ СО РАН, 2009. $210 \mathrm{c}$. 


\section{Материалы IV Международного семинара «Письменное наследие \\ и актуальные проблемы истории и культуры монгольских народов», посвященного 100-летию со дня рождения Пурбо Балдановича Балданжапова}

Дашиева 2009б - Дашиева Л. Д. Улигеры хори-бурят // Вестник Томского государственного университета. 2009. № 322. С. 72-74.

Дашиева 2014 - Дашиева Л. Д. Материалы П. Б. Балданжапова как источник изучения песенной традиции хори-бурят // Культура Центральной Азии: письменные источники. Вып. 8. Улан-Удэ: Изд-во БНЦ СО РАН, 2014. С. 65-76.

Дашиева 2017 - Дашиева Л. Д. Обрядовая песенная традиция западных бурят. Иркутск: Оттиск, 2017. 448 с.

Дугаров 1964 - Дугаров Д. С. Бурятские народные песни. Песни хори-бурят. УланУдэ: БКНИИ СО АН СССР, 1964. 443 с.

Дугаров, Куницын 1997 - Дугаров Д. С., Кунищын О. И. Буряты // Музыкальная культура Сибири: в 3-х т. Т. 1. Кн. 1. Новосибирск: НГК, 1997. С. 336-404.

Дугаров 1991 - Дугаров Д. С. Исторические корни белого шаманства (на материале обрядового фольклора бурят). М.: Наука, 1991. 300 с.

Магтаал, үреэл, соло 1993 - Магтаал, үреэл, соло / сост. С. Д. Бабуев. Улаан-Үдэ: Буряадай номой хэблэл, 1993. 80 с. (На бур. яз.)

Нумаа 2003 - Нумаа А. А. Буряад-монгол арадай дуунууд. Улан-Удэ: Буряад үнэн, 2003. 320 с. (На бур. яз.)

Черемисов 1973 - Черемисов К. М. Бурятско-русский словарь. М.: Сов. энциклопедия, $1973.804 \mathrm{c.}$

Чистохин 1894 - Чистохин Я. Хвалебная песнь монголов первой прибежавшей лошади на хурале // Известия Восточно-Сибирского отдела ИРГО. Иркутск, 1894. T. XXV. №№ 2-3. С. 139-140.

Шагдаров, Черемисов 2006 - Шагдаров Л. Д., Черемисов К. М. Бурятско-русский словарь. В 2 т. Т. 1. Улан-Удэ: Респ. тип., 2006. 636 с.

Шагдаров, Черемисов 2008 - Шагдаров Л. Д., Черемисов К. М. Бурятско-русский словарь. В 2 т. Т. 2. Улан-Удэ: Респ. тип., 2008. 708 с.

Шагдарон, Очиров 1909 - Шагдарон С.-Д., Очиров Б.-Д. Игры и увеселения агинских бурят // Сборник в честь 70-летия Г. Н. Потанина. СПб.: Тип. В. Ф. Киршбаума, 1909. C. $465-482$.

\section{References}

Babuev S. D. (comp.) Magtaal, Üreel, Solo. Ulan-Ude: Buryatia Book Publ., 1993. 80 p. (In Bur.)

Baldanzhapov P. B. Uligers of Aga Buryats. Ulan-Ude: Buryatia Book Publ., 1961. 127 p. (In Bur. and Russ.)

Cheremisov K. M. Buryat-Russian Dictionary. Moscow: Sovetskaya Entsiklopediya, 1973. 804 p. (In Bur. and Russ.)

Chistokhin Ya. Mongolian glorifying song for a horse to win the Khural race. Izvestiya Vostochno-Sibirskogo otdela IRGO. 1894. Vol. XXV. No. 2-3. Pp. 139-140. (In Russ.)

Dashieva L. D. Buryat Traditional Music Culture. Coursebook Ulan-Ude: Respublikanskaya Tipografiya, 2005. 188 p. (In Russ.)

Dashieva L. D. Exploring the Khori Buryat song tradition: Materials collected by P. Baldanzhapov. In: Culture of Central Asia. Written Sources. Collected papers. Vol. 8. 2014. Pp. 65-76. (In Russ.)

Dashieva L. D. Uligers of Khori Buryats. Tomsk State University Journal. 2009. No. 322. Pp. 72-74. (In Russ.)

Dashieva L. D. Western Buryats: The Ritual Song Tradition Reviewed. Irkutsk: Ottisk, 2017. 448 p. (In Russ.)

Dashieva L. D. Yohor Circle Dance of the Buryats: Historical, Ethnographic, Modal, and Rhythmic Aspects. Ulan-Ude: Buryat Scientific Center (SB RAS), 2009. 210 p. (In Russ.) 
Dugarov D. S. Buryat Folk Songs: Songs of Khori Buryats. Ulan-Ude: Buryat Comprehensive Research Institute (SB USSR Acad. of Sc.), 1964. 443 p. (In Russ.)

Dugarov D. S. Historical Roots of White Shamanism: A Case Study of Buryat Ritual Folklore. Moscow: Nauka, 1991. 300 p. (In Russ.)

Dugarov D. S., Kunitsyn O. I. Buryats. In: Music Culture of Siberia. In 3 vols. Vol. 1 Book 1. Novosibirsk: NGK, 1997. Pp. 336-404. (In Russ.)

Numaa A. A. Folk Songs of Buryat Mongols. Ulan-Ude: Buryaad Ünen, 2003. 320 p. (In Bur.)

Shagdaron S.-D., Ochirov B.-D. Games and festivities of Aga Buryats. In: Celebrating the $70^{\text {th }}$ Birthday of G. N. Potanin. Collected papers. St. Petersburg: V. Kirschbaum, 1909. Pp. 465-482. (In Russ.)

Shagdarov L. D., Cheremisov K. M. Buryat-Russian Dictionary. In 2 vols. Vol. 1. Ulan-Ude: Respublikanskaya Tipografiya, 2006. 636 p. (In Bur. and Russ.)

Shagdarov L. D., Cheremisov K. M. Buryat-Russian Dictionary. In 2 vols. Vol. 2. Ulan-Ude: Respublikanskaya Tipografiya, 2008. 708 p. (In Bur. and Russ.) 